\section{Strategi Penerjemahan pada Laman Resmi Sekretariat Kabinet Republik Indonesia}

Titis Kris Pandu Kusuma ${ }^{1}$, Sajarwa ${ }^{2}$

${ }^{1}$ Mahasiswa Pascasarjana IImu Linguistik UGM ${ }^{2}$ Dosen Fakultas IImu Budaya UGM

1Surel: titiscris@ymail.com

\begin{abstract}
INTISARI
Penelitian ini bertujuan untuk mendeskripsikan bagaimana strategi penerjemahan pada berita pemerintah yang dimuat dalam laman resmi Sekretariat Kabinet Republik Indonesia dari bahasa Indonesia ke bahasa inggris pada laman yang sama. Peneliti menggunakan teori dari Mona Baker (2001). Data merupakan 152 dari 15 teks berita yang terdiri dari kata, frase, atau kalimat yang mengandung unsur strategi penerjemahan. Sumber data berasal dari laman resmi Sekretariat Kabinet Republik Indonesia yaitu www.setkab.go.id dalam rentang waktu 6-10 April 2018 dan 6-12 September 2018. Metode dalam penelitian ini merupakan deskriptif komparatif, mengumpulkan data dengan observasi non-partisan dan teknik simak catat. Kemudian dianalisis dengan metode padan translasional. Lalu hasil penyajian data dengan bentuk formal dan informal. Dari hasil analisis terdapat tujuh strategi penerjemahan dan ada satu strategi yang paling banyak digunakan pada berita pemerintah yang dimuat dalam laman resmi Sekretariat Kabinet Republik Indonesia. Strategi dengan kata pinjaman dan pinjaman dengan penjelasan yang paling banyak digunakan oleh penerjemah dalam menerjemahkan berita pemerintah pada laman resmi Sekretariat Kabinet Republik Indonesia. Hal tersebut dikarenakan demi kepentingan kejelasan makna. Penerjemah memasukkan informasi tambahan di dalam teks terjemahannya karena pembaca memerlukan informasi tersebut.
\end{abstract}

Kata kunci: Strategi Penerjemahan Mona Baker, Berita Pemerintah, Laman Resmi, Sekretariat Kabinet Republik Indonesia.

\title{
PENDAHULUAN
}

Lalu lintas informasi semakin ramai karena berbagai bangsa di dunia semakin paham akan pentingnya berbagi informasi, pengetahun, berita dan lain sebagainya untuk kemajuan di berbagai sektor. Dunia menjadi semakin mudah karena berbagai kegiatan mulai dijalankan dalam skala global. Oleh karena itu, terjemahan kian hari kian penting karena komunikasi dan berbagi pengetahuan di tingkat global semakin menjadi kebutuhan. Dalam konteks tersebut, terlihat jelas bahwa dibutuhkan strategi penerjemahan yang baik untuk memainkan peran yang sangat penting karena hal itu merupakan instrumen untuk mengkomunikasikan pesan secara tepat dan akurat ke berbagai belahan dunia. Kebijakan politik, program pembangunan, dokumen penelitian, proyek dan lain sebagainya dapat diterjemahkan ke dalam berbagai bahasa dan menjadi konsumsi pembaca dunia. 
Artikel ini mencoba mendeskripsikan bagaimana strategi penerjemahan dan yang paling dominan digunakan pada berita pemerintah yang dimuat dalam laman resmi Sekretariat Kabinet Republik Indonesia, www.setkab.go.id, dari bahasa Indonesia ke bahasa inggris pada laman yang sama sebagai objek kajian. Berita pemerintah pada laman resmi Sekretariat Kabinet Republik Indonesia dipilih karena pentingnya sebuah Negara memberikan informasi positif tentang berita-berita kenegaraan ke mancanegara, terlebih lagi berita tersebut diterjemahkan oleh asisten deputi bidang naskah dan terjemahan yang bertanggungjawab pada penerjemahan dokumen dan berita resmi pemerintah. Sehingga terjemahan tersebut dapat dikatakan baik dan dapat dilihat bagaimana strategi penerjemahannya agar adanya keselarasan wacana antara teks sumber dengan teks sasaran.

Menurut Newmark (1988) definisi tentang terjemah adalah menerjemahkan suatu teks kedalam bahasa lain sesuai dengan yang dimaksud pengarangnya. Nida dan Taber (1969:12) mengatakan Terjemahan adalah menghasilkan padanan natural yang paling dekat dari pesan bahasa sumber ke dalam bahasa penerima, pertama dari segi makna dan kedua dari segi gaya. Menurut Suryawinata \& Hariyanto (2003:67), strategi penerjemahan adalah taktik penerjemah untuk menerjemahkan kata atau kelompok kata, atau mungkin kalimat penuh apabila kalimat tersebut tidak bisa dipecah lagi menjadi unit yang lebih kecil untuk diterjemahkan.

Berdasarkan teori Mona Baker (2011) dalam bukunya "In Other Words" terdapat 8 strategi penerjemahan, yaitu:

(1) penerjemahan dengan kata yang lebih umum (superordinat), strategi ini biasanya digunakan ketika Bsa tidak memiliki kata yang spesifik,

(2) penerjemahan dengan kata yang lebih netral atau ekspresif, Strategi ini digunakan ketika BSa memiliki kata detail dan sepsifik

(3) penerjemahan dengan alih kebudayaan, Strategi ini digunakan ketika BSa menggunakan kata yang lebih akrab dalam masyarakat sehingga dijadikan sebagai substitusi.

(4) penerjemahan dengan kata pinjaman atau kata pinjaman dengan penjelasan, strategi kata pinjaman yang mempertahankan kata-kata BSu tersebut secara utuh, baik bunyi maupun tulisannya ke dalam Bsa

(5) penerjemahan dengan parafrase menggunakan kata yang berkaitan, Startegi ini digunakan ketika sebuah konsep dikenal secara leksikal namun berbeda dalam bentuk.

(6) penerjemahan dengan parafrase menggunakan kata yang tidak berkaitan, Strategi ini digunakan ketika konsep BSa tidak tersedia secara leksikal di BSa. Paraprase dapat dilakukan, salah satunya, dengan memodifikasi superordinat.

(7) penerjemahan dengan penghapusan atau penghilangan kata, Strategi penghilangan kata ini dilakukan ketika penjelasan yang terlalu panjang memiliki kemungkinan mengganggu kenyamanan pembac, dan 
(8) penerjemahan dengan menggunakan gambar atau ilustrasi, Strategi ini digunakan ketika BSa tidak memiliki padanan kata yang merujuk sesuatu yang bisa diilustrasikan, khususnya ketika space terbatas, seperti pada kemasan sebuah produk.

Dalam penerjemahan juga melibatkan unsur politik serta keterlibatan kekuasan Negara. Situasi penerjemahan sangat beragam dan selalu terkait dengan perosalan sosial, politik, ilmu pengatahaun dengan tujuan utamanya pembaca umum/ internasional. Untuk mengetahui berita kenegaraan, pembaca bisa mengetahui dari teks berita cetak maupun digital. Menurut Nasution dalam Alief (2008:1), Berita adalah laporan tentang peristiwa-peristiwa yang terjadi yang ingin diketahui oleh umum, dengan sifat aktual, terjadi di lingkungan pembaca, mengenai tokoh terkemuka, akibat peristiwa tersebut berpengaruh terhadap pembaca. Menurut Sumadiria (2005:6). Berita adalah laporan tercepat mengenai idea atau fakta terbaru yang benar, menarik dan penting bagi sebagian khalayak, melalui media berkala seperti surat kabar, radio, televisi, atau media internet.

Penelitian dalam bidang penerjemahan sudah banyak dilakukan orang. Terutama penelitian yang mengambil objek karya sastra seperti novel, cerpen, puisi, dan film. Namun objek penelitian berupa teks berita seperti berita pemerintah masih sedikit dan jarang dilakukan. Penulis menemukan beberapa penelitian terdahulu dibidang penerjemahan diantaranya dilakukan oleh Cipto Wardoyo (2015) dalam penelitiannya yang dimuat pada Jurnal Nasional Prasasti berjudul Strategi penerjemahan istilah-Istilah Pragmatik dalam Buku "Principles of Pragmatics" Karangan Geofrey Leech ini menganalisis metode dan strategi penerjemahan dalam penerjemahan buku Principles of Pragmatics karangan Geofrey Leech. Dari data strategi penerjemahan ditemukan bahwa teknik atau strategi naturalisasi paling dominan digunakan. Istilah-istilah pragmatik banyak diterjemahkan dengan menggunakan teknik peminjaman (borrowing) secara naturalisasi karena sulit untuk menerjemahkan istilah-istilah tersebut ke dalam padanan kata yang tepat di dalam bahasa Indonesia.

Raja Rachmawati (2013) dalam penelitiannya yang dimuat dalam Jurnal Nasional Kemendikbud, Jurnal Bahasa dan Sastra, Balai Bahasa Riau, meneliti puisi yang berjudul Strategi Penerjemahan Puisi-Puisi Chairil Anwar oleh Raffel dalam Buku The Complete Prose and Poetry of Chairil Anwar. Penelitian ini dianalisis menggunakan strategi penerjemahan secara umum yang dikemukakan oleh Newmark, Vinay dan Dalberhet, Baker, and Hoed dan strategi penerjemahan puisi oleh Andre Lavefere. Hasil analisis menunjukkan bahwa strategi penejemahan umum yang digunakan adalah strategi penerjemahan modulasi, calque atau penerjemahan literal, kesepadanan deskriptif, penerjemahan dengan kata generik atau kata yang lebih umum. Sedangkan strategi penerjemahan puisi yang digunakan oleh Raffel adalah penerjemahan 
metris, penerjemahan rima atau sajak, penerjemahan bait secara bebas, dan penerjemahan interpretasi.

Penelitian ini merupakan deskriptif komparatif. Data merupakan 152 yang terdiri dari kata, frase, atau kalimat yang mengandung unsur strategi penerjemahan dari 15 teks berita, sumber data berasal dari laman resmi Sekretariat Kabinet Republik Indonesia yaitu www.setkab.go.id dalam rentang waktu 6-10 April 2018 dan 6-12 September 2018. Metode dalam mengumpulkan data adalah observasi non-partisan dan teknik simak catat. Kemudian dianalisis dengan metode padan translasional. Lalu hasil penyajian data dengan bentuk formal dan informal. Peneliti membuka laman resmi tersebut menggunakan jaringan internet kemudian mengamati dan memperhatikan berita-berita yang diunggah pada laman tersebut. Setelah itu peneliti mengunduh langsung teks berita sumber bahasa Indonesia dan juga terjemahannya pada bahasa Inggris menggunakan teknik simak catat yang dikemukaan oleh Sudaryanto. Kemudian dianalisis dengan metode padan translasional. Metode padan adalah metode yang digunakan dalam upaya menemukan kaidah dalam tahap analisis data yang alat penentunya di luar, terlepas, dan bukan menjadi bagian dari bahasa yang bersangkutan. Alat penentunya menggunakan bahasa lain disebut translasional karena cara analisisnya menggunakan bahasa sasaran yaitu bahasa Inggris. Lalu hasil penyajian data dengan bentuk formal dan informal. Contohnya dengan kode angka 01/t1/p2 yang artinya, nomer data pertama/teks sumber ke1/paragraf ke-2.

\section{HASIL DAN PEMBAHASAN}

Dari hasil analisis dapat ditemukan bahwa penerjemah pada laman resmi Sekretariat Negara Republik Indonesia menggunakan hampir semua strategi yang dikemukakan Mona Baker dalam bukunya 'In Other words'. Namun hanya satu strategi yang tidak digunakan yaitu strategi 'penerjemahan menggunakan gambar atau ilustrasi. Hal ini dikarenakan teks sumber merupakan teks berita resmi kenegaraan yang tidak perlu menggunakan gambar atau ilustrasi dalam proses penerjemahannya.

Berikut merupakan pembahasan dari hasil analisis strategi penerjemahan pada Laman resmi Sekretariat Kabinet Republik Indonesia:

\section{Kata yang lebih umum (superordinat)}

No.Data $58 / \mathrm{t} 6 / \mathrm{p} 1$

Bsu: Kodrat bangsa Indonesia, menurut Presiden, memang terlahir di atas keragaman budaya, adat, dan bahasa

Bsa: Indonesia's identity, the President added, is its diversity in culture, custom, and language 
No.Data $20 /$ t2/p1

Bsu: Presiden Jokowi: Infrastruktur Dibangun Untuk Menghubungkan 17.000 Pulau di Indonesia

Bsa: President Jokowi: Infrastructure Built to Connect the Islands in Indonesia

No.Data 38/t4/p19

Bsu: dan menjadikan negara Indonesia menjadi negara maju, pemenang, dan berdiri sejajar dengan bangsa-bangsa lain di dunia.

Bsa: to make our country turn a developed country which can compete with other countries," the President concluded.

Pada contoh tersebut, penerjemah menggunakan strategi penerjemahan menggunakan kata yang lebih umum seperti pada data nomor 58, 'kodrat bangsa Indonesia' menjadi 'Indonesia's identity' dikarenakan pada Bsa tidak terdapat kata spesifik untuk menerjemahkan 'kodrat' sehingga istilah 'identity' merupakan kata umum yang sudah cukup sepadan yang dipilih oleh penerjemah untuk menerjemahkan kata tersebut. Kata Indentity mengandung makna 'identitas' yang sepadan maknanya dengan kata 'kodrat'.

Kemudian pada contoh nomor 20, penggunaan kata '17.000 pulau' diterjemahkan ke bahasa sasaran menjadi "the islands" merupakan penggunaan kata umum agar pembaca memahami ada banyak pulau di Indonesia yang akan dibangun infrastrukturnya tanpa perlu menulis secara detail jumlah pulau tersebut. Dan pada contoh nomor 38, "negara maju, pemenang, dan berdiri sejajar dengan bangsa-bangsa lain di dunia" pada bahasa sasaran menjadi "a developed country which can compete with other countries" yang sudah cukup sepadan dengan kata umum karena negara yang dapat bersaing dengan negara lain tentu saja mengandung makna negara tersebut maju, menang, dan berkembang.

\section{Kata yang lebih netral atau ekspresif}

No. Data: 05/t1/p7

Bsu: Ditambahkan Presiden,

Bsa: For the record,

No.Data 29/t4/p8

Bsu: bahwa tantangan global mengharuskan umat Hindu untuk semakin cerdas,

Bsa: that global challenges require Hindu people in particular and Indonesian people in general to be more intelligent, 
Dari contoh data nomor 05 tersebut, sebenarnya penerjemah bisa saja menerjemahkan kata 'Ditambahkan' menjadi 'in addition' atau sejenisnya, namun penerjemah memilih menggunakan kata 'For the record' yang memiliki kata spesifik atau sepadan maknanya dengan kata yang ada pada teks sumber.

Pada contoh data nomer 29 tersebut, penerjemah menggunakan strategi penerjemahan menggunakan kata yang lebih netral karena terjemahan pada Bsa merujuk pada kata yang spesifik dan juga tujuan penerjemah tidak hanya untuk 'umat hindu' saja, namun juga untuk seluruh orang Indonesia yang beragama Hindu maupun bukan yang menganut agama Hindu. Itulah sebabnya pada Bsa menjadi 'Hindu people in particular and Indonesian people'. Penerjemah menggunakan kata netral agar pembaca di Bsa dapat menerima pesan secara menyeluruh dan netral dari Bsu.

\section{Alih kebudayaan}

No. Data: $04 / \mathrm{t} 3 / \mathrm{p} 10$

Bsu: dan supaya PKK menggerakkan lagi Posyandu.

Bsa: and reminded Family Welfare Movement (PKK) to organize more Posyandu.

No.Data 014/t3/p2

Bsu: kader Posyandu.

Bsa: Integrated Health Post (Posyandu)

No.Data 16/t3/p5

Bsu: Pos Pelayanan Terpadu (Posyandu)

Bsa: Integrated Service Posts (Posyandu)

Pada contoh tersebut, penerjemah menggunakan strategi penerjemahan menggunakan alih kebudayaan karena BSa tidak memiliki makna yang proporsional terkait konsep budaya tertentu. Hal ini dikarenakan di Negara lain mungkin tidak ada istilah 'PKK' dan 'posyandu'. Istilah ini hanya terdapat pada budaya Negara Indonesia saja. Sehingga dalam penerjemahan di Bsa di sesuaikan dengan istilah 'Family Welfare Movement' dan 'Integrated Health Post' atau 'Integrated Service Posts'. Kata tersebut digunakan untuk menerjemahkan karena penerjemah harus menggunakan kata yang lebih akrab dan sepadan dalam masyarakat Bsa untuk dijadikan sebagai substitusi.

\section{Kata pinjaman atau kata pinjaman dengan penjelasan}

No. Data: 02/t1/p10

Bsu: Sidratulmuntaha

Bsa: Sidratunmuntaha 
No.Data: 08/t1/p2

Bsu: Isra Mikraj

Bsa: Isra Mi'raj is the ascension of Prophet Muhammad to Sidrat al-Muntaha, where the Prophet directly spoke with God, advising a spiritual regimen of five-times daily prayer.

No.Data: $10 / \mathrm{t} 3 / \mathrm{p} 6$

Bsu: tempenya juga lokal

Bsa: tempeh (a fermented soybean cake)

Pada contoh data nomor 02 tersebut, penerjemah menggunakan strategi kata pinjaman yang mempertahankan kata-kata BSu tersebut secara utuh, baik bunyi maupun tulisannya ke dalam Bsa seperti pada istilah 'Sidratulmuntaha'. Strategi ini biasa digunakan untuk kata atau frase yang berhubungan dengan nama orang, nama tempat, nama majalah, nama jurnal, nama lembaga, gelar dan istilah-istilah pengetahuan yang belum ada pada kosakata BSa. Alasan mengapa strategi ini digunakan adalah untuk menunjukkan penghargaan terhadap kata-kata tersebut. Alasan lain, karena belum ditemuinya padanan di dalam Bsa.

Pada contoh data nomer 08 dan nomor 10 menggunakan kata pinjaman dengan penjelasan karena penerjemah sengaja menambahkan informasi agar pembaca dari berbagai latar belakang diseluruh dunia dapat memahami konteks kalimat dan berita yang dimaksut. Sehingga pembaca pada Bsa dapat memahami jika Isra Mi'raj adalah sebuah kejadian kenaikan dimana Rasulullah bertemu dengan Tuhan untuk menerima perintah shalat 5 waktu. Serta tempeh adalah sejenis makanan yang terbuat dari kedelai. Ini merupakan makanan khas Indonesia. Jadi penerjemah memasukkan informasi tambahan di dalam teks terjemahannya agar pembaca dari berbagai belahan dunia dapat mengetahui tentang jenis makanan Indonesia. Hal ini juga dapat menambah wawasan pembaca serta mengangkat 'tempe' ke bahasa Internasional. Informasi tambahan ini bisa diletakkan di dalam teks, di bagian bawah halaman (catatan kaki) atau di bagian akhir dari teks (Newmark, 1988: 91-92). Dengan begitu, pembaca dapat mengetahui informasi secara utuh.

\section{Parafrase kata yang berkaitan}

No Data 013/tz/p2

Bsu: Acara ini dihadiri warga yang terdiri dari ibu hamil, ibu menyusui, balita, dan kader Posyandu.

Bsa: Nursing mothers, pregnant women, toddlers and Integrated Health Post (Posyandu) cadres were among those who joined the event.

No.Data: $21 / \mathrm{t} 3 / \mathrm{p} 1$

Bsu: Cegah 'Stunting', Presiden Jokowi: Pemerintah Fokus Pemberian Makanan Tambahan, Tapi Lokal

Bsa: Gov't Provides Local-Based Supplementary Food to Prevent Stunting 
Pada contoh tersebut, penerjemah menggunakan strategi penerjemahan parafrase kata yang berkaitan dengan sepadan karena menyesuaikan gramatika pada Bsa. Pada contoh data nomer 013 tertulis di awal kalimat 'acara ini dihadiri (...)' Pada gramatika Bsu hal tersebut sudah sesuai dengan gramatika, namun pada Bsa belum sesuai dengan gramatika. Untuk itu penerjemah harus menerjemahkan sesuai Bsa dengan Subjek sebagai awal kalimat menjadi 'Nursing mothers, pregnant women (...)"

Begitupun juga pada contoh data nomer 021, biasa di awali dengan Frase 'Cegah Stunting', namun pada gramatika Bsa tidak bisa di awali dengan frase, melainkan harus di awali dengan Subjek, yaitu 'Government'. Dengan begitu, pembaca pada Bsa dapat memahami pesan Bsu dengan baik karena penerjemah sudah menerjemahkan secara sepadan. Startegi ini digunakan ketika sebuah konsep dikenal secara leksikal namun berbeda dalam bentuk atau tata bahasanya.

\section{Parafrase kata yang tidak berkaitan}

No.Data $07 / \mathrm{t} 1 / p_{5}$

Bsu: terang Presiden seraya menambahkan, dirinya juga ikut mendorong penyelenggaraan KTT Luar Biasa OKI di Istanbul pada bulan Desember 2017, yang menentang pengakuan sepihak Amerika Serikat terhadap Yerusalem sebagai ibu kota Israel. Posisi Indonesia, lanjut Presiden Jokowi juga sangat tegas bahwa pengakuan sepihak Amerika Serikat tersebut telah melanggar berbagai resolusi Dewan Keamanan dan Majelis Umum PBB.

Bsa: the President said, adding that Indonesia also helped to organize the OIC Extraordinary Summit in Istanbul in December 2017 to discuss Palestine issues.

No.Data 32/t4/p12

Bsu: Umat Hindu, menurut Presiden, diminta untuk selalu memegang teguh ajaran wasudewa khutum bakam atau kita semua bersaudara yang menekankan arti penting persaudaraan sejati, karena semua berasal dari sumber yang sama yakni dari Tuhan Yang Maha Esa.

Bsa: the President said, adding that Hindus are asked to always emphasize the importance of brotherhood.

Pada contoh data nomor 7, penerjemah menggunakan strategi penerjemahan menggunakan parafrase tidak berkaitan. Hal ini dapat terlihat karena konsep pada BSU seperti pandangan politik Presiden Indonesia yang "juga sangat tegas bahwa pengakuan sepihak Amerika Serikat tersebut telah melanggar berbagai resolusi Dewan Keamanan dan Majelis Umum PBB" tidak diterjemahkan secara leksikal di Bsa. Pada contoh tersebut terdapat parafrase beberapa kata dan kalimat dari teks sumber yang hanya menjadi satu kalimat saja yaitu 'to discuss Palestine issue'. Hal ini mungkin dilakukan penerjemah agar isu sensisif seperti hal tersebut tidak 
menggangu hubungan Negara Indonesia dengan Negara lain di mancanegara ketika diterjemahkan, sehingga penerjemah memparafrase terjemahan di Bsa dengan kata atau kalimat yang tidak berkaitan secara spesifik.

Pada contoh data nomor 32, makna bahasa sumber dengan bahasa sasaran sudah cukup sepadan yang mengandung pentingnya persaudaraan, namun pada bahasa sasaran tidak dijelaskan secara spesifik sehingga menggunakan parafrase kata yang tidak berkaitan dengan bahasa sumber seperti ajaran teguh dari wasudewa khutum bakam dan pentingnya persaudaraan karena semua manusia adalah ciptaan Tuhan Yang Maha Esa. Sehingga penerjemah menggunganakan parafrase yang tidak berkaitan antara bahasa sumber dengan bahasa sasaran.

\section{Penghapusan atau penghilangan kata}

No. Data: 011/t1/p1

Bsu: Presiden Joko Widodo (Jokowi) mengemukakan, bahwa dengan selalu memohon rida Allah SWT dengan pikiran yang jernih dan kerja keras, pemerintah terus berusaha keras meningkatkan kesejahteraan masyarakat, menuntaskan kemiskinan, meningkatkan pemerataan, dan meningkatkan kemampuan ekonomi umat.

Bsa: The Indonesian Government continues to improve welfare of the people, reduce poverty, increase equity, and improve economy of the people, according to President Joko "Jokowi" Widodo.

No. Data: 012/t1/p2

Bsu: di Istana Kepresidenan Bogor, Jawa Barat, Selasa (10/4) petang.

Bsa: at Bogor Presidential Palace, West Java, Tuesday (10/4).

Pada contoh tersebut, penerjemah menggunakan strategi penerjemahan dengan penghapusan atau penghilangan kata karena hal ini bisa dilakukan selama tidak mengubah makna penting dalam sebuah teks. Pada Bsu makna penting yang harus disampaikan pada Bsa adalah programprogam pemerintah untuk memajukan kesejahteraan masyarakat. Jadi, frase 'bahwa dengan selalu memohon rida Allah SWT dengan pikiran yang jernih dan kerja keras' dan juga istilah 'petang' boleh dihilangkan atau tidak diterjemahkan letika penjelasan yang terlalu panjang memiliki kemungkinan mengganggu kenyamanan pembaca.

\section{KESIMPULAN}

Dari hasil analisis tersebut dapat terlihat jelas bahwa terjadi beberapa perubahan pada teks terjemahan berita pemerintah pada laman resmi Sekretariat Kabinet Republik Indonesia dari Bsu ke Bsa. Perubahan tersebut terjadi karena penerjemah menggunakan kata yang lebih umum dan ada juga kata yang lebih netral. Penerjemah juga berusaha tetap mempertahankan istilah 
pada Bsu agar menghargai kata tersebut dengan menggunakan kata pinjaman. Disisi lain, penerjemah juga menggunakan terjemahan kata yang lebih akrab dalam Bsa dengan mengalihkan kata-kata budaya karena belum adanya padanan yang sesuai di Bsa. Penerjemah juga menambahkan dan menghapus terjemahan dari Bsu ke Bsa agar pembaca pada Bsa dapat memahami konteks berita yang tersebar keseluruh dunia tersebut dan juga bertujuan untuk keselarasan wacana dalam Bsu ke Bsa. Dari beberapa strategi tersebut, strategi dengan kata pinjaman yang paling banyak digunakan oleh penerjemah dalam menerjemahkan berita pemerintah pada laman resmi Sekretariat Kabinet Republik Indonesia. Hal tersebut dikarenakan demi kepentingan kejelasan makna. Penerjemah memasukkan informasi tambahan di dalam teks terjemahannya karena pembaca memerlukan informasi tersebut.

\section{DAFTAR PUSTAKA}

Alief. 2008. "Konsep Dasar Berita". Http://aliefnews.wordpres.com/2008/01/11/konsep-dasarberita/ diakses tanggal 6 Mei 2018

Baker, Mona. 1992. In Other Words: A Course Book on Translation. New York: Routledge

Catford, J.C. 1965. A Linguistics Theory of Translation. England: Oxford University Press.

Larson, Mildred L. 1998. Meaning Based Translation: A guide to Cross Language Equivalence. USA : University Press of America

Newmark, Peter. 1988. A Textbook of Translation. Hertfordshire: Prentice Hall International English Language Teaching.

Newmark, Peter. 1981. Approaches to Translation. Oxford: Pergamon Press.

Newmark, Peter. 1991. About Translation. Clevedon: Multilingual Matters Ltd.

Newmark, Peter. 1993. Paragraph on Translation. Clevedon: Multilingual Matters Ltd.

Nida Eugene and Taber. 1969. Science of Translation in Language. Vol 5 Number 3. New York: American Bible Society

Nida, Eugene Albert. 2001.Context In Translating. Netherland: John Benjamins

Rachmawati, Raja. 2013. Strategi Penerjemahan Puisi-Puisi Chairil Anwar oleh Raffel dalam Buku The Complete Prose and Poetry of Chairil Anwar. Jurnal Bahasa dan Sastra-Balai $\begin{array}{lllll}\text { Bahasa Riau. Kemendikbud Ro } & \text { No. }\end{array}$ http://ejurnalbalaibahasa.id/index.php/madah/article/view/536 diakses tanggal 2 April 2018

Sudaryanto. 1993. Metode dan Aneka Teknik Analisis Bahasa: Pengantar Penelitian Wahana Kebudayaan secara Linguistis. Yogyakarta: Duta Wacana University Press.

Sumadiria. 2005. Jurnalistik Indonesia, Menulis Berita dan Feature: Panduan Praktis Jurnalis Profesional. Bandung: PT. Remaja Rosdakarya

Suryawinata, Zuchridin dan Sugeng Hariyanto. 2003. Translation: Bahasa Teori dan Penuntun Praktis Menerjemahkan. Yogyakarta: Penerbit Kanisius. 
Venuti, Lawrence. 2004. The Translation Studies Reader. London: Routledge

Vinay, J. P., \& Darbelnet, J. (2000). A Methodology for Translation. In Venuti (Ed.), The Translation Studies Reader (pp. 84-93). London and New York: Routledge.

Wardoyo, Cipto. 2015. Strategi penerjemahan istilah-Istilah Pragmatik dalam Buku "Principles of Pragmatics" Karangan Geofrey Leech. Seminar Nasional II-Kajian Pragmatik dalam Berbagai Bidang. https://jurnal.uns.ac.id/prosidingprasasti/article/viewFile/123/105 diakses tanggal 3 April 2018 